JURNAL RESPIRASI

JR

Vol. 2 No. 3 September 2016

\title{
Seorang Penderita Siliko Tuberkulosis dengan Penyulit Pneumotoraks
}

\author{
Winariani Koesoemoprodjo, Vinodini Merinda \\ Departemen Pulmonologi dan Ilmu Kedokteran Respirasi, Fakultas Kedokteran Universitas Airlangga/RSUD Dr. Soetomo
}

\begin{abstract}
Background: Silicosis is a lung disease caused by the work because of respirable crystalline silica. Often occurs in workers mining gold, iron, tin, granite, sandstone, slate, foundries, cement, ceramics and glass. The risk of silicosis develop into lung tuberculosis (TB) is higher than patients without silicosis. Another complication of silicosis is secondary spontaneous pneumothorax. Case: A man, 45 years old with a history of work as a bricklayer for 5 years with complaints shortness of breath since three days before admitted to the hospital, chest pain in the right hemithorax, and had chronic cough. Patients is on ATD therapy. From radiographic there is collapse lung, it was shown collapse line on the right hemithorax, and fibroinfiltrat with multiple cavities on both hemithorax. Patients then got chest tube insertion and evaluation for 3 weeks, but the lung has not expanded. From thoracoscopy, there is fibrotic band on the pleural space with conclution right trapped lung. From forcep biopsy on visceral pleura showed a widened alveolar epithelial layer coated with a pile of inflammatory lymphocytes and dust pigments. From broncoscopy, there is chronic lung inflamation. Spectrophotometric analysis from BAL specimens results showed a silica content of 4.25 ppm $\mathrm{SiO}_{2}$ from left $\mathrm{BAL}$ an $14.34 \mathrm{ppm} \mathrm{SiO} \mathrm{O}_{2}$ on the right $\mathrm{BAL}$. Furthurmore, this patient got pleurodesis using betadine agent and continue the ATD. Evaluation the lung is fully expanded. Conclusion: This case illustrates the secondary spontaneous pneumothorax as a complication of silicotuberkulosis. No drug has proven effective for silicosis. Treatment is aimed to the disease complications that occur, in this case is secondary spontaneous pneumothorax and lung TB. Prevention at workplaces that have a risk of silicosis is very important.
\end{abstract}

Key words. silicotuberculosis, secondary spontaneous pneumothorax

Correspondence: Winariani Koesoemoprodjo, Departemen Pulmonologi dan Ilmu Kedokteran Respirasi, Fakultas Kedokteran, Universitas Airlangga/RSUD Dr. Soetomo. Jl. Mayjen. Prof Dr. Moetopo 6-8 Surabaya 60286. E-mail:winariani_07@yahoo.com

\section{PENDAHULUAN}

Penyakit paru kerja adalah penyakit yang paling banyak dijumpai diantara semua penyakit akibat kerja. Hal ini disebabkan rata-rata waktu yang dihabiskan di tempat kerja \pm 8 jam/hari, di mana akan terhirup udara \pm 3500 L udara termasuk partikel debu atau bahan pencemar lain yang terdapat di dalamnya. Partikel debu lingkungan kerja dibagi menjadi debu organik (nabati, hewani), debu inorganik (pertambangan, industri logam, keramik), dan gas iritan (industri petrokimia, farmasi). ${ }^{1}$

Silikosis adalah penyakit paru kerja yang disebabkan oleh karena terhirup kristal silika. Tempat kerja dengan risiko terkena silikosis antara lain: pertambangan emas, besi, timah, granit, pasir, batu tulis, pengecoran logam, pabrik semen, keramik dan gelas. Berdasarkan data NIOSH (National Institute of Occupational Safety and Health) di Amerika Serikat, sekitar 1,7 juta pekerja terpajan silika dengan rata-rata 1500 sampai 2360 orang yang menderita silikosis setiap tahunnya. ${ }^{2}$ Studi surveilans yang dilakukan di Michigan, Amerika Serikat, antara tahun 1987 hingga 1995 menunjukkan bahwa sebanyak lebih dari $60 \%$ pekerja pabrik/pertambangan yang telah bekerja selama minimal 20 tahun, sebanyak 577 pekerja menderita silikosis. Tahun 1996 silikosis dilaporkan terjadi pada 60 orang dari 1072 pekerja pabrik mobil. $^{2}$

Studi epidemiologi yang dilakukan pada abad kedua puluh menunjukkan adanya hubungan antara silikosis 
dengan TB paru. Risiko silikosis berkembang menjadi TB paru adalah sebesar 2,8 sampai 39 kali lebih tinggi daripada pasien tanpa silikosis, karena peningkatan kerentanan penderita silikosis terhadap tuberkulosis. ${ }^{3}$ Silikosis akut dan silikosis terakselerasi adalah bentuk silikosis yang memiliki insidens tertinggi dalam hubungannya dengan TB. Diagnosis silikotuberkulosis rata-rata 7,6 tahun setelah pajanan silikosis berakhir. Dalam tiga dari empat penelitian, terjadinya TB berhubungan langsung dengan jumlah kumulatif pajanan, serta lamanya waktu bekerja di pertambangan. ${ }^{4}$

Komplikasi lain dari silikosis adalah pneumotoraks spontan sekunder. Pneumotoraks spontan sekunder sering berhubungan dengan silikosis kronis dan silikosis terakselerasi dengan fibrosis masif progresif. Kasus pneumotoraks spontan sekunder sering terjadi unilateral. ${ }^{5}$

Gejala klinis silikosis pada stadium awal biasanya tidak memberikan gejala yang spesifik. Sehingga biasanya pasien baru datang dengan komplikasi berupa sesak napas. Seperti pada kasus ini, di mana pasien datang dengan keluhan sesak napas yang setelah dievaluasi didiagnosis menderita TB disertai pneumotoraks spontan sekunder, yang merupakan komplikasi dari silikosis.

\section{KASUS}

Seorang laki-laki, 45 tahun, suku Jawa, warga negara Indonesia, seorang tukang batu serabutan selama 5 tahun, datang dengan keluhan sesak napas sejak tiga hari sebelumnya, disertai nyeri dada sebelah kanan, terdapat batuk lama sejak empat bulan sebelumnya, kemudian dipasang selang dada selama kurang lebih tiga minggu, namun dari evaluasi paru masih belum mengembang.

Pada pemeriksaan toraks didapatkan secara inspeksi pengembangan paru asimetris dengan sisi kanan kesan tertinggal. Pada palpasi didapatkan fremitus raba menurun pada hemitoraks kanan. Pada perkusi didapatkan hipersonor pada 1/3 atas lapang paru kanan. Pemeriksaan auskultasi terdengar suara vesikuler yang menurun pada $1 / 3$ atas lapang paru kanan, tidak didapatkan wheezing maupun ronki.

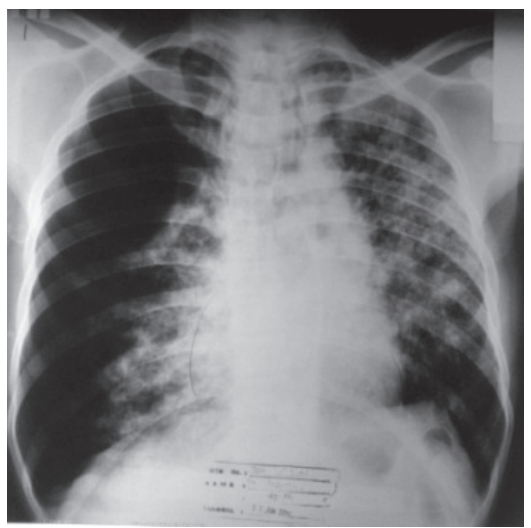

Gambar 1. Foto toraks pada saat masuk RS. Karang Tembok.

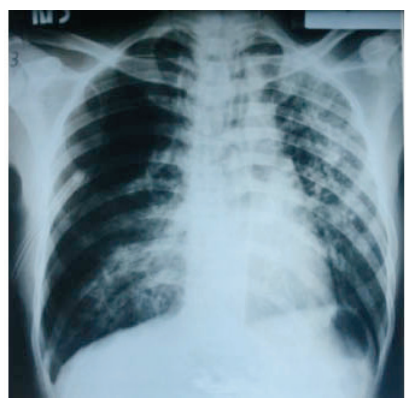

Gambar 2. Foto toraks pada setelah pemasangan selang dada.
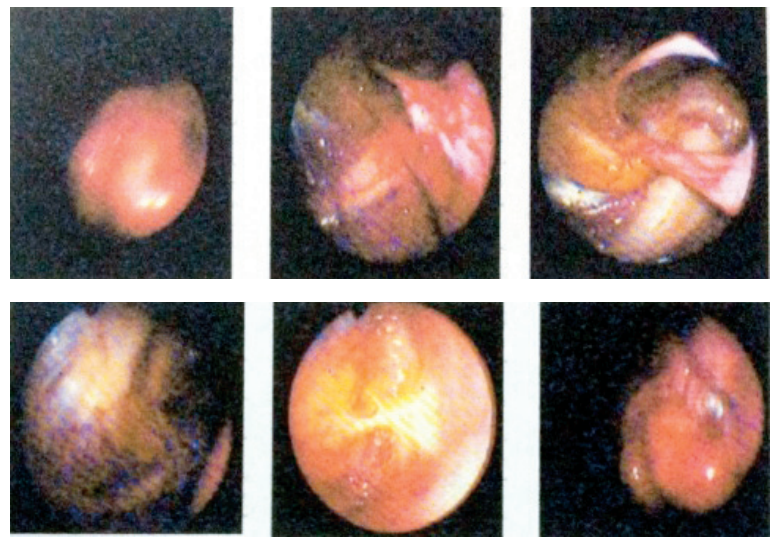

Gambar 3. Hasil torakoskopi adalah trapped lung pada paru kanan dan terdapat fibrotic band antara pleura parietalis dan pleura viseralis.

Data pemeriksaan foto toraks menunjukkan gambaran pneumotoraks kanan (Gambar 1) dan tampak pada foto toraks gambaran pneumotoraks kanan yang terpasang selang dada (Gambar 2).

Karena paru masih belum mengembang setelah 30 hari perawatan, selanjutnya dilakukan tindakan torakoskopi. Dari torakoskopi tampak pada rongga pleura terdapat fibrotic band yang menghubungkan pleura parietalis dan viseralis, tidak didapatkan fistel, dan pleura viseralis terlihat berdungkul-dungkul, yang disimpulkan terdapat trapped lung paru kanan pada penderita ini (Gambar 3). Biopsi forcep pada pleura viseralis menunjukkan potongan jaringan terdiri dari alveoli yang melebar dilapisi selapis epitel dengan timbunan radang limfosit serta tampak sedikit dust pigmen.

Hasil FOB tampak keradangan kronis paru, dan dari pemeriksaan analisa spektrofotometri spesimen BAL menunjukkan adanya kandungan silika sebesar 4,25 ppm $\mathrm{SiO}_{2}$ pada BAL kiri dan 14,34 ppm $\mathrm{SiO}_{2}$ pada BAL kanan. Selanjutnya dilakukan tindakan pleurodesis dengan menggunakan agent betadine. Evaluasi klinis penderita paska pleurodesis dilakukan pada saat perawatan poliklinis Kondisi pengembangan paru menunjukkan hasil di mana sudah tidak tampak garis kolaps paru kanan dan keluhan sesak tidak dirasakan kembali oleh penderita. Pengobatan TB paru berakhir setelah 6 bulan pengobatan dan penderita mengalami perbaikan klinis. 


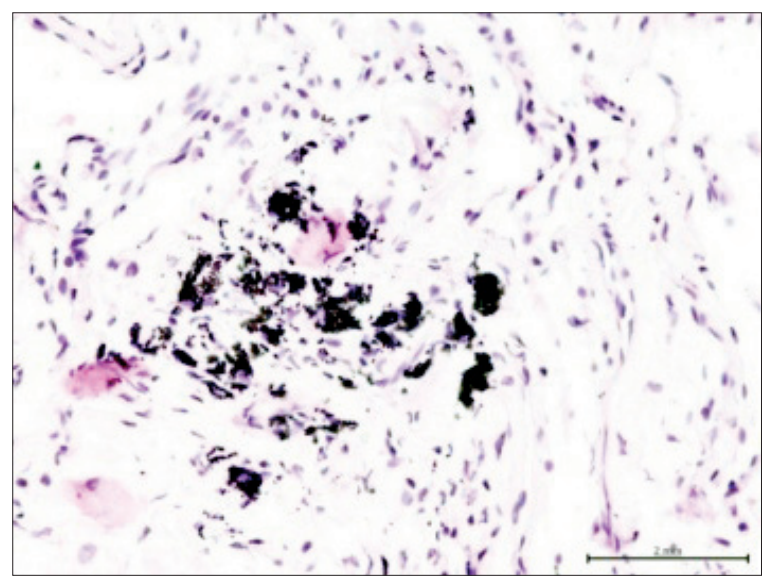

Gambar 4. Hasil PA dengan pembesaran 200 menunjukkan potongan jaringan terdiri dari alveoli yang melebar dilapisi selapis epitel dengan timbunan radang limfosit serta tampak sedikit dust pigmen.

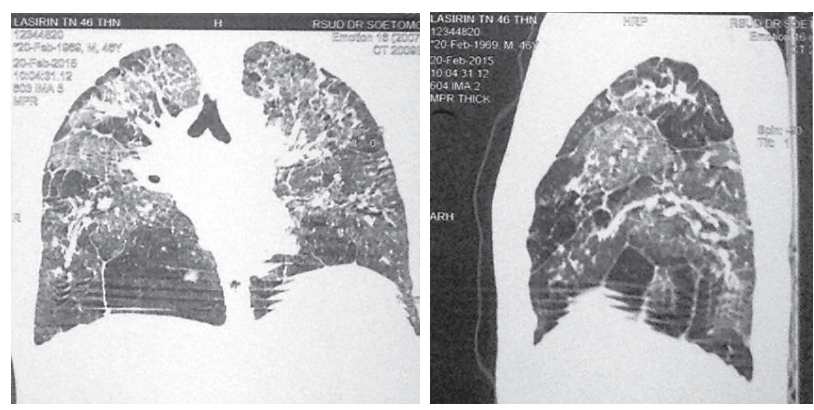

Gambar 5. HRCT Toraks.

Evaluasi foto toraks 4 bulan setelah pengobatan OAT lengkap, tidak tampak lagi gambaran pneumotoraks kanan dan kesan menyokong gambaran silikosis. Sementara hasil pemeriksaan HRCT toraks tanpa kontras mengesankan gambaran TB Paru, centri lobular, para septal dan multiple bulous emphysematous di lobus superior kanan kiri, dan juga tampak kesan bronkiektasis tipe silindrik segmen anterior lobus superior kanan dan segmen superior lobus inferior kanan. Secara keseluruhan kondisi akhir penderita mengalami perbaikan klinis dan dapat melakukan aktivitas keseharian secara mandiri.

Terdapat gambaran TB Paru, centri lobular, para septal dan multiple bulous emphysematous di lobus superior kanan kiri, dan juga tampak kesan bronkiektasi tipe silindrik segmen anterior lobus superior kanan dan segmen superior lobus inferior kanan.

\section{DISKUSI}

Silikosis adalah penyakit paru kerja yang disebabkan oleh karena terhirup kristal silika. Pekerja sandblasting, pengeboran, tunneling, penggilingan tepung silika, pembuatan keramik, dan lain sebagainya memiliki predisposisi untuk terjadinya silikosis.
Silika adalah sekelompok mineral alami, terbagi menjadi dua yaitu, non kristalin (amorfous silika) dan kristalin (kristalin silika). Terdapat tujuh kristalin silika, yang terdiri dari silikon dan oksigen ( $\mathrm{SiO} 2)$ dengan campuran $\mathrm{Al}, \mathrm{Fe}, \mathrm{Mn}, \mathrm{Mg}, \mathrm{Ca}$, dan $\mathrm{Na}$ di dalamnya, termasuk kuarsa, kristobalit, moganite, tridimit, melanoflogit, koesit, dan stishovit. Di mana berdasarkan sifat fibrogenik debu silika, terbagi menjadi sangat fibrogenik yaitu tridimit, kristobalit, dan tetrahedron, sedangkan yang termasuk non fibrogenik yaitu kuarsa, koesit, stishovit, dan oktahedron. ${ }^{1}$ Batu-batuan seperti granit, serpihan, dan batu pasir terdiri dari $67 \%$ kuarsa. Bentuk yang paling umum adalah bentuk kristalin silika, yang sering didapatkan pada pertambangan, peledakan, dan konstruksi dapat mengakibatkan paparan silika yang signifikan. Silikon dioksida terbentuk melalui ikatan kovalen yang kuat, serta memiliki struktur lokal yang jelas, yaitu empat atom oksigen terikat pada posisi sudut tetrahedral di sekitar atom pusat yaitu atom silikon. ${ }^{5}$

\section{Patogenesis Silikosis}

Patogenesis silikosis terutama terjadi pada interaksi antara sel-sel paru dengan partikel silika yang terinhalasi serta respons sekunder yang dicetuskan oleh interaksi tersebut. Bagian permukaan partikel silika berinteraksi dengan makrofag alveoli, limfosit dan neutrofil menimbulkan inflamasi, proliferasi fibroblas dan deposit bahan-bahan matriks jaringan ikat dalam jumlah yang besar. ${ }^{7}$ Partikel yang ditimbun di alveoli semula terletak pada fagosom tetapi karena efek toksik silika maka fagosom hancurdan partikel silika terletak bebas dalam sitoplasma. Enzim lisosom dilepaskan dari fagosom yang hancur sehingga menyebabkan makrofag cepat mati dan isinya termasuk partikel silika terlepas ke jaringan ekstraseluler. Makrofag akan berkumpul lebih banyak setelah memakan debu silika yang kemudian akan terbunuh pula. Efek sitotoksik silika adalah faktor penting dalam pembentukan jaringan fibrosis. Kematian makrofag akan merangsang pembentukan kolagen oleh fibroblast di jaringan sekitarnya sehingga terbentuk nodul yang mengandung silika bebas di jaringan interstisial dekat bronkiolus. ${ }^{6}$

\section{Gejala Klinis}

Berdasar dosis dan jangka waktu sejak terjadinya pajanan, lesi silikosis diklasifikasikan menjadi 3, yaitu: ${ }^{8}$ (1) Silikosis Kronis: Silikosis kronik adalah bentuk yang paling sering ditemukan, yang terjadi bertahun-tahun, selama lebih dari 15 tahun setelah terpajan debu silika dengan tingkat pajanan relatif rendah. Biasanya tidak ditemukan gejala atau kelainan pada pemeriksaan fisik; (2) Silikosis Terakselerasi: Silikosis terakselerasi terjadi karena pajanan debu silika dalam jumlah besar namun dalam jangka waktu antara 5-10 tahun. Paparan silika dengan konsentrasi tinggi selama waktu yang relatif singkat dalam beberapa tahun menghasilkan bentuk yang lebih progresif; (3) Silikosis Akut: Silikosis akut adalah bentuk silikosis yang paling jarang ditemukan. Silikosis akut terjadi karena pajanan debu silika berat dalam jumlah yang sangat besar 
dalam waktu pajanan mungkin bervariasi dari beberapa minggu sampai empat atau lima tahun.

Pada kasus ini, penderita berdasarkan gejala klinis menderita silikosis terakselerasi karena pajanan debu silika antara 5-10 tahun, dengan tingkat pajanan yang rendah disertai dengan gejala klinis keluhan batuk berdahak sejak 4 bulan sebelum dirawat, dan terjadi komplikasi berupa tuberkulosis yang disebut sebagai silikotuberkulosis dengan penyulit pneumotoraks spontan sekunder, di mana komplikasi inilah yang membuat penderita datang berobat ke rumah sakit.

\section{Siliko tuberkulosis}

Paparan debu kristalin silika menyebabkan beberapa komplikasi, namun siliko-tuberkulosis, khususnya, adalah penyakit yang tetap tinggi pada daftar prioritas masalah kesehatan kerja di negara-negara berpenghasilan rendah dan masih terjadi di beberapa negara berpendapatan tinggi. ${ }^{9}$

Hubungan antara silikosis dan tuberkulosis telah dipelajari sejak awal abad kedua puluh. Risiko berkembang menjadi TB paru dilaporkan 2,8-39 kali lebih tinggi pada pasien dengan silikosis daripada pasien tanpa silikosis. ${ }^{10} \mathrm{Di}$ Brasil, prevalensi $52 \%$ TB paru, dalam bentuk fibrosis masif progresif, baru-baru ini dilaporkan pada pasien dengan silikosis. ${ }^{11}$ Mengenai hubungan antara bentuk silikosis dengan penyakit infeksi mikobakteria, studi literatur internasional telah menunjukkan bahwa silikosis akut dan silikosis terakselerasi memiliki insiden tertinggi. ${ }^{12}$

Mekanisme yang mungkin menyebabkan peningkatan kerentanan penderita silikosis terhadap tuberkulosis adalah partikel silika yang tertimbun di alveoli akan dimakan oleh makrofag tetapi karena efek toksik silika maka makrofag cepat mati dan partikel silika akan terlepas ke jaringan ekstraseluler. ${ }^{12}$ Partikel silika akan dimakan oleh makrofag lain yang kemudian terbunuh pula. Silika dengan dosis subletal juga mengganggu kesanggupan makrofag untuk menghambat pertumbuhan kuman tuberkulosis karena makrofag adalah faktor utama dalam membuat daya tahan terhadap tuberkolosis sehingga alasan meningkatnya kerentanan penderita silikosis terhadap tuberkulosis menjadi jelas. ${ }^{13}$

\section{Komplikasi Pneumotoraks dari Silikosis}

Pneumotoraks spontan sekunder adalah salah satu komplikasi silikosis pada pleura. Pneumotoraks spontan sering berhubungan dengan silikosis kronis dengan fibrosis masif progresif. Kasus pneumotoraks spontan sekunder sering terjadi unilateral, dan dapat terjadi bilateral pada beberapa kasus. Beberapa kasus pneumotoraks bilateral dilaporkan pada silikosis terakselerasi. Pada pneumotoraks spontan sekunder dapat terjadi pula pada silikosis akut yang disertai bula. ${ }^{14}$ Paparan silika terhadap paru menghasilkan produk inflamasi yang menyebabkan jaringan fiber yang elastik pada dinding alveoli yang kemudian membentuk bleb. Fibrosis masif pada jaringan paru menghasilkan $a$ stiff nondistensible dengan peningkatan elastik rekoil. Pneumotoraks spontan sekunder dapat terjadi disebabkan oleh ruptur pada bula dan dapat disertai peningkatan elastik rekoil pada jaringan paru. Pneumotoraks merupakan komplikasi fibrosis paru difus dan penyakit bulosa. ${ }^{14}$ Ini sering terjadi pada silikosis terakselerasi dan silikosis akut, di mana hal tersebut dapat menyebabkan komplikasi fatal. ${ }^{6}$

Kristal silika yang berukuran kurang dari $1 \mu \mathrm{m}$ diyakini paling patogen. Kristal silika yang masuk ke dalam paru kemudian menyebabkan retensi partikel silika pada lobus atas paru. Kontak langsung jaringan dengan partikel silika menyebabkan ketidakseimbangan antara produk respons inflamasi yang kemudian memengaruhi keelastisitasan dinding alveolar serta pembentukan bleb pada alveoli di lobus atas atau sehingga terjadi kerusakan pada alveoli dan disfungsi tipe II sel sehingga paru tidak dapat mengembang. ${ }^{14}$

Penyebab pneumotoraks pada pasien ini kemungkinan disebabkan oleh ruptur bleb akibat inflamasi silika yang muncul bersamaan dengan infeksi tuberkulosis paru. Perjalanan infeksi tuberkulosis paru juga mendorong terbentuknya kavitas atau bleb yang akhirnya pecah dan mengakibatkan terjadinya pneumotoraks. Selain itu mekanisme lain yang mendasari diantaranya adalah batuk di mana dalam hal ini terjadi peningkatan tekanan alveolar yang melebihi tekanan interstisial paru dan menyebabkan udara dari alveoli berpindah ke rongga interstisial kemudian menuju hilus dan menyebabkan pneumomediastinum, dan kemudian udara akan berpindah melalui pleura parietalis pars mediastinal ke rongga pleura sehingga menimbulkan pneumotoraks. ${ }^{15}$

\section{Diagnosis}

Diagnosis silikosis ditegakkan berdasarkan riwayat pekerjaan dengan pajanan silika, lamanya pajanan silika, serta adanya temuan radiografik pada foto toraks menentukan jenis silikosis. ${ }^{3}$ Dari temuan radiografik pada foto toraks silikosis dibagi menjadi dua yaitu, simple silikosis dan PMF (progressive massif fibrosis). Di mana gambaran radiologis pada simple silikosis adalah adanya opasitas berbentuk nodul, berukuran kecil (diameter $<10 \mathrm{~mm}$ ), kadang berbentuk irregular, pada bagian atas paru. Sedangkan gambaran radiologis pada PMF, yaitu adanya opasitas berbentuk nodul, berukuran lebih besar (diameter $>10 \mathrm{~mm}$ ), terletak pada paru bagian atas sampai tengah. ${ }^{16}$ Opasitas berbentuk cabang, yang mewakili fibrosis peribronkiolar, merupakan tanda-tanda awal silikosis. Perubahan pleura juga telah diamati pada silikosis, yang utama adalah efusi pleura (12\%), penebalan pleura (58\%), dan invaginasi pleura. Termasuk atelektasis yang ditemukan pada beberapa kasus fibrosis masif progresif pada silikosis kronis. ${ }^{17}$

Pada temuan radiologi silikosis kronis tanpa komplikasi adalah perselubungan berbentuk lingkaran yang halus pada lapangan paru biasanya menyerupai tipe " $r$ ". Ukuran perselubungan kurang dari 10mm. Perselubungan simetris pada kedua paru dan terletak pada paru lobus atas, kadang-kadang terjadi kalsifikasi seperti mikrolitiasis. Diawali dengan pembesaran kelenjar pada hilus terlebih 
dahulu kemudian diikuti dengan kelainan pada parenkim paru. Kalsifikasi pada kelenjar getah bening pada hillus seperti "eggshell" hanya terjadi pada $10 \%$ dari kasus tersebut. Walaupun ditemukan hanya pada sebagian kecil kasus tetapi sangat menyokong diagnosis silikosis. Pada silikosis terakselerasi gambaran foto toraks mirip dengan silikosis kronis. Sedangkan pada silikosis akut lebih sering ditemukan gambaran difus pada interstisial, dan jarang ditemukan opasitas berbentuk nodul, air bronkogram dapat ditemukan. ${ }^{17}$

Silikosis tanpa komplikasi ditandai dengan adanya opasitas kecil berbentuk bulat pada foto toraks, klasifikasi berdasarkan International Labour Organization (ILO) yang digunakan untuk interpretasi gambaran radiologis kelainan pada parenkim difus. ${ }^{1}$

High Resolution Computed Tomography (CT) dada lebih sensitif dibanding foto toraks untuk melihat silikosis sederhana. Pada silikosis terkomplikasi, CT Scan memberikan hasil lebih jelas (kaviti). Walaupun kaviti pada silikosis dapat terjadi tanpa infeksi mikobakterium tetapi kemungkinan penyakit ini perlu diperhatikan. ${ }^{18}$ Namun, meskipun sensitivitas lebih tinggi, namun hanya digunakan dalam kasus di mana ada keraguan secara klinis maupun radiologis. ${ }^{17}$

Pada kondisi tertentu, diperlukan diagnosis pasti pajanan bahan di lingkungan kerja dengan analisis bahan biologi (sputum, bronchoalveolar lavage/BAL, biopsi transbronkial atau biopsi paru terbuka) untuk melihat debu mineral atau produk metabolismenya. Pemeriksaan BAL membantu menegakkan diagnosis. Pada pemeriksaan BAL dapat terlihat debu di dalam makrofag dan jenis debu kemungkinan dapat diidentifikasi menggunakan mikroskop elektron. Pada silikosis, makrofag yang ditemukan dalam BAL berisi partikel granit yang semakin lama riwayat pajanan terhadap debu granit maka akan semakin banyak ditemukan makrofag tersebut. Selain itu, nodul silikotik dapat ditemukan pada pemeriksaan histopatologi silikosis. ${ }^{19}$ Biopsi pada jaringan paru akan nampak bentukan silika, sehingga dapat membedakan fibrosis massif progresif akibat silikosis atau kanker paru, tuberkulosis, dan lainlain. ${ }^{3}$

Pada kasus ini, penderita dengan riwayat pekerjaan sebagai tukang batu selama 5 tahun dan tukang kayu selama 25 tahun. Dari temuan radiologis foto toraks terdapat bercak kecil irregular dengan diameter 1,5-3 mm, dengan kerapatan kategori 2, yaitu terlihat beberapa perselubungan irregular kecil dan corakan paru tidak terlalu jelas dan dengan perselubungan kasar jenis A, yaitu terdapat perselubungan dengan diameter masing-masing lebih dari $1 \mathrm{~cm}$, tetapi apabila dijumlahkan tidak melebihi $5 \mathrm{~cm}$. Dari hasil pemeriksaan analisa spektrofotometri spesimen BAL menunjukkan adanya kandungan silika sebesar 4,25 ppm $\mathrm{SiO}_{2}$ pada BAL kiri dan 14,34 ppm $\mathrm{SiO}_{2}$ pada BAL kanan. Dari hasil biopsi forcep pada pleura viseralis yang berdungkul memberikan hasil tidak tampak tanda keganasan. Pada gambaran mikroskopis menunjukkan potongan jaringan terdiri dari alveoli yang melebar dilapisi selapis epitel dengan timbunan radang limfosit serta tampak sedikit dust pigmen.

Penatalaksanaan terpenting adalah pencegahan terjadinya silikosis. Pencegahan dilakukan pada tempat kerja yang mempunyai risiko silikosis seperti penggunaan air pada beberapa tempat kerja untuk mencegah debu yang beterbangan. Hal yang penting adalah mengontrol kadar debu sehingga tidak melebihi ambang batas yang direkomendasikan. Ventilasi yang baik di tempat kerja harus ada agar udara bersih dapat masuk dan debu tidak menumpuk di tempat kerja. Oleh karena itu penting untuk meningkatkan kewaspadaan terhadap terjadinya silikosis pada pekerja dengan risiko tinggi. ${ }^{18}$

Belum ada obat yang terbukti efektif untuk silikosis. Pengobatan ditujukan pada komplikasi penyakit yang terjadi. Terapi yang dilakukan sama seperti pengobatan obstruksi saluran napas, infeksi, pneumotoraks, hipoksemia dan gagal napas. Bila penyakit telah menimbulkan gejala maka diberikan terapi simtomatis seperti pemberian oksigen dan antibiotik apabila terdapat infeksi. ${ }^{18}$

Prognosis penyakit tergantung luas lesi, respons parenkim terhadap silika, banyaknya lesi fibrosis, progresivitas penyakit dan kegagalan organ. ${ }^{19}$

\section{KESIMPULAN}

Telah dilaporkan seorang laki-laki, 45 tahun, bekerja sebagai tukang batu selama 5 tahun dan menjadi tukang kayu di pabrik mebel datang dengan keluhan sesak napas dirasakan sejak tiga hari sebelum masuk Rumah Sakit Karang Tembok, disertai nyeri dada sebelah kanan dengan riwayat mengangkat beban berat. Terdapat batuk lama sejak empat bulan yang lalu disertai dahak yang berwarna putih. Pada penderita juga terdapat keluhan penurunan nafsu makan, penurunan berat badan dan disertai keringat malam. Kemudian pasien dirujuk ke RSUD Dr. Soetomo karena setelah terpasang selang dada selama kurang lebih tiga minggu, dari hasil evaluasi disebutkan bahwa paru masih belum mengembang. Penderita didiagnosis sebagai silikotuberkulosis dengan penyulit pneumotoraks spontan sekunder kanan dan sedang dalam pengobatan TB paru fase lanjutan. Belum ada obat yang terbukti efektif untuk silikosis. Pengobatan ditujukan pada komplikasi penyakit yang terjadi, yaitu pneumotoraks spontan sekunder dan TB paru. Dalam evaluasi selanjutnya paru telah mengembang sempurna.

\section{DAFTAR PUSTAKA}

1. K. Winariani, Buku Ajar Ilmu Penyakit Paru: Penyakit paru kerja dan pencemaran udara, Wibisosno MJ., Winariani, Hariadi S., Departemen Ilmu Penyakit Paru FK Unair-RSUD Dr. Soetomo Surabaya 2013: 126-145.

2. Barbozal CE, Winter DH, Seiscento M, et al. Tuberculosis and silicosis: epidemiology, diagnosis and chemoprophylaxis, J Bras Pneumol. 2008; 34 (11): 961-968. 
3. Mason RJ, Broaddus VC, Martin TR, et al. Murray \& Nadels's Textbook of Respiratory Medicine: Environmental And Occupational Disorders, Saunders 2010: 1586-1596.

4. Calvert G M, Rice F L, Boiano J M, et al. Occupational silica exposure and risk of various diseases: an analysis using death certificates from 27 states of the United States, Occup Environ Med 2003; 60: 122-129.

5. P. Mishra, ES. Jacob, D. Basu, MK Panigrahi, V. Govindaraj, Bilateral spontaneous pneumothorax in chronic silicosis: a case report, Case Rep Pathol.2014: 561861.

6. Hinshaw HC, Murray JF. Silicosisin diseaseof the chest. In: Murray editor. Textbook of respiratory medicine. Philadelphia: WB Saunders Company; 1998. P. 716-22.

7. Davis GS, Occupational disorders of the lung: Silikosis. Hendrick DJ, Burge S, Beckett WS, Churg A, WB Saunders, 2002. P 105-12.

8. Seaton A., Occupational lung disease: Silicosis. WB Saunders, 1996. P. 250-322.

9. Susanto AD., Pneumokoniosis, J. Indon Med assoc, 2011, 61: 503-510.

10. Hnizdo E, Murray J. Risk of pulmonary tuberculosis relative to silicosis and exposure to silica dust in South African gold miners. Occup Environ Med. 1998; 55(7): 496-502. Erratum in: Occup Environ Med 1999; 56(3): 215-6.

11. Corbett EL, Churchyard GJ, Clayton T, Herselman P, Williams B, Hayes R, et al. Risk factors for pulmonary mycobacterial disease in
South African gold miners. A case-control study. Am J Respir Crit Care Med. 1999; 159(1): 94-9.

12. Adverse effects of crystalline silica exposure. American Thoracic Society Committee of the Scientific Assembly on Environmental and Occupational Health. Am J Respir Crit Care Med. 1997; 155(2): 761-8.

13. Gardner Lu., Silicosis and relationship to toberculosis, Am Rev Respir Dis, 1987; 115: 221-34

14. I. Mohebbi, E. Hassani, S. Salarilak, and A.R. Bahrami, Do bullae and emphysema increase risk of pneumothorax in silicosis? Journal of Occupational Medicine and Toxicology, 2007 vol. 2 no. 1, p. 8.

15. Sahn SA, Heffner JE. Spontaneus pneumothorax. N Eng J Med 2000; 342: 868-74

16. Banks DE, Interstisial Lung Disease: The health effects of silica and coal dust exposure, $5^{\text {th }}$ edition, Schwarz, King, 2011, p. 499-541.

17. Antao VC, Pinheiro GA, Terra-Filho M, Kavakama J, Müller NL. High-resolution CT in silicosis: correlation with radiographic findings and functional impairment. J Comput Assist Tomogr. 2005; 29(3): 350-6.

18. Ikhsan ML, Marlond R, Swidarmoko B. Bunga Rampai Penyakit Paru Kerja dan Lingkungan: Silikosis, Ikhsan M, Yunus Faisal, Susanto AD., FK UI 2009: 27-38.

19. Rees D, Murray J., Silica, silicosis and tuberculosis, Int J Tuberc Lung Dis. 2007 May, 11(5): 474-84. 